\title{
Research Overview on Urban Land Use Change Based on Remote Sensing Images
}

\author{
Cheng-fan $\mathrm{LI}^{1}$, Senior Member IACSIT, Jing-yuan $\mathrm{YIN}^{1,2 *}$ and Lan LIU
}

\begin{abstract}
With the accelerated urbanization process, urban land use has changed dramatically. High-resolution remote sensing technology is widely used in urban land use change monitoring and high-resolution mapping. In this study, the current use of high-resolution remote sensing technology to monitor urban land use change research status summary and analysis, which for the urban construction and the harmonious development of the ecological environment and provide scientific basis for decision making.
\end{abstract}

Index Terms-urban; land use change; high resolution remote sensing

\section{INTRODUCTION}

City as the center of human activity is social - economic natural complex ecosystem, as a regional core of the system has strong vitality, with the modern industrialization and urbanization process accelerated, continuing to expand around $[1,2,3]$. With the deepening of reform and opening up, China has entered a phase of great development of urbanization. Urbanization is an inevitable result of social and economic development, the development and promotion of the socio-economic development and prosperity. Urbanization, transformation of human activities has become one of the main natural environments.

With urbanization, the increase in urban population, urbanization level, leading to the city "internal restructuring" and "peripheral geographic expansion", the great changes, that great changes in urban land use. Because of the limited land area, location and quality of fixed differences and other natural features and land use on the continuity of time and space relationships, leading to the use of land resources, the process was extensive and open land, labor and capital together in different ways to form different land use patterns. Changes in urban land use patterns directly affect the atmospheric circulation, hydrological processes, the

Manuscript received December 15, 2010. This work was supported by the Key project of Shanghai leading academic disciplines of China (Grant No.J50103), and partially by the Key Project of the National Technology Support Program of China (Grant No.2008BAC38B03) and Key Program of Shanghai Science and Technology Committee (Grant No.08DZ2292200). The authors gratefully acknowledge this support.

Cheng-Fan LI. School of Computer Engineering and Science, Shanghai University, Shanghai, CO 200072, China;(phone: 0086-13621734010; fax: 0086-21-50761080; e-mail: david-0904@163.com)

Jing-Yuan YIN. School of Computer Engineering and Science, Shanghai University, Shanghai, CO 200072, China; and Earthquake Administration of Shanghai, Shanghai, CO 200062, China. (Corresponding author, Phone: 0086-21-66743308)

Lan LIU. School of Foreign Languages, Shandong Foreign Languages Vocational College, Rizhao, CO 276826, China. microclimate, soil, biodiversity and environmental pollution, the normal development processes that affect the harmonious development of human society and ecological environment and sustainable development. From a global perspective, the process of urbanization caused by urban land use change and ecological degradation have led to global climate change, global surface in the past 100 years occurred in $40 \%$ of the change in surface air temperature in the last century increased of $0.6^{\circ} \mathrm{C}$.

Remote sensing technology as a direct contact in case of not on target for remote observation can be efficient, comprehensive, real-time understanding of the changes in urban development, urban development and timely grasp of the new, specific, subtle change information, the rational planning, building and guidance[4,5]. Most of the research objectives of the city is small and the complex and diverse, high-resolution remote sensing technology for its high spatial resolution, time, high resolution, large amount of information contained in the more obvious characteristics of surface features and other advantages of Pop, so in the urban development dynamic monitoring and effective means of extracting thematic information. Therefore, urban land use change in remote sensing studies, for the rational use and protection of land resources and ecological environment for sustainable development is of great practical significance. At present, remote sensing technology applications have become a city planning, management and modernization and management of an important indicator of the level of information.

\section{RESEARCh SignificANCE}

And of traditional urban land use change monitoring compared, using high-resolution remote sensing technology to monitor more efficient time-saving, saving a lot of manpower, material resources and time, improve the urban land use database building a database and update efficiency. For example, when the city found in remote sensing images from within a region to change the land use change, can change very quickly find out, and by the GIS technology to build the database to be updated, which greatly improved the quality of the data update efficiency. Using high-resolution remote sensing data can make large-scale ground image maps. Using high-resolution remote sensing technology can clearly find that subtle changes in the process of urban development, urban planning, and transportation management department can handle a good interpretation of remote sensing images based on rapid and accurate decisions. 


\section{RESEARCH STATUS}

Currently, urban land use changes to urban land use in terms of thematic information extraction, information extraction methods commonly used feature has the following two: First, visual interpretation methods, such as remote sensing using two-phase image of the city dynamic monitoring of land use, human-computer interactive method using remote sensing image interpretation, and multi-temporal remote sensing image overlay, and finally the use of geographic information system software for a variety of analysis and map output. This approach to the inclusion of human knowledge, interpretation of high precision, but it is more complicated, and the need for remote sensing interpretation were more likely interpretation of knowledge and experience. Second, there is a post-classification comparison method, post-classification comparison method is the time to classify remote sensing images, respectively, on a comparative analysis of classification results, access to land use change information, which is a far the most commonly used method. In addition, with high-resolution remote sensing data sources and study the emergence of an increasingly wide range also appeared in a variety of research methods, such as the image difference method, principal component analysis, image fusion method, vegetation index method.

Many cities have domestic and foreign remote sensing satellites for dynamic monitoring of urban expansion and urbanization of which the city has been the expansion of the main areas of urban studies, people worked hard, through, revealing the formation and evolution of urban land use internal and external driving mechanism, Comparing the characteristics of different types of differences in urban expansion [6,7]. The use of remote sensing and geographic information systems, spatial information technology for monitoring urban expansion and dynamic simulation of space-time analysis is the main direction of development of remote sensing the city. Since 1972, the first U.S. satellite launch has been a land-based, remote sensing, research began to get in to the application of current, high-resolution remote sensing technology at home and abroad on the use of urban land use change to carry out dynamic monitoring of more mature technology and achieved fruitful results.

\section{A. Domestic Research}

China in the seventies and eighties of last century to carry out remote sensing dynamic monitoring of the environment in Tianjin, the Yangtze, the Yellow River delta dynamics studies. With SPOT5, IKONOS, QuickBird and other high-resolution satellite put into operation, using remote sensing survey of the macro as well as land resources began to inner city and other micro-regional monitoring and thematic information extraction and other aspects of change. In recent years, with the high-resolution satellites have been put into use, the relevant software platform continues to progress and improvement of remote sensing monitoring of the approach, methods and content are constantly monitoring the deepening and refinement, macroeconomic monitoring is also moving to microscopic changes of direction[8]. At present, the domestic macro-regions than the land use monitoring and research more, and achieved remarkable results.

Remote sensing technology in urban land use changes in the application of the main land use types around the identification and monitoring of changes two aspects of information carried. The improvement of remote sensing classification methods of remote sensing technology has been important areas of research; remote sensing information extraction directly affects the level of detail of urban land use change process and results of the study. However, the remote sensing classification methods, interpretation skills, work experience, to grasp the extent of knowledge of the error, making the results of image interpretation unsatisfactory; In addition, remote sensing technology can not accurately reflect the title change due to property caused by changes in land use.

However, many domestic scholars remained committed to urban remote sensing monitoring of land use change, and achieved many results. Li X using satellite remote sensing technology for the expansion of the Pearl River Delta Urban Development Corridor dynamic monitoring process, and by compactness index and entropy of the quantitative description of the laws of urban growth and expansion of space during [9]. Zhang congruent according to the 1990, 1995 and 2000, three image data obtained by remote sensing platform in Beijing 90 years of data of land use change, combined with historical meteorological data, hydrological data and spatial, attribute data, spatial analysis using GIS methods and mathematical statistics, a comprehensive analysis of Beijing in 1990 - 2000 space between the land use change and its driving force [10].With China's sustained economic development of small towns, the land use conflicts have become increasingly prominent, small town land use change has become increasingly important. Wang, Huanghua Town, such as the use of land use in 1989 and 2003 aerial photo database orthophotos in GIS technical support, Huanghua Town, summed up the distribution of land-use change and the basic features $[11,12]$.

But in the more urban areas within the micro remote monitoring of land use is relatively small, mainly due to the complex diversity of urban surface, making the city there are a large number of remote sensing images of the "foreign body with the spectrum" and "the same object different spectrum "phenomenon, automatic classification of the computer caused great difficulties, thus increasing the city to establish and update the database more difficult. In the remote sensing of urban land use change is to understand the purpose of monitoring land use, land use is reasonable to know, update the underlying database the city to find the power factor of land use change and its eco-environmental effects resulting from the analysis, develop appropriate response, so that the process of urban development land use change in human society and ecological environment to the harmonious development of the direction of change. Overall, since the 90 s of last century, remote sensing of the city began to develop in depth. The trend is to trace the process of urbanization and the evolution of history, explore the trends in urban development, urban development plan for the development of scientific basis [13].

For urban remote sensing research, although many 
scholars in the land use change and expansion mode and so do a lot of large, more comprehensive study, but there are still some shortcomings, mainly in multi-use statistical data, not very accurate reflect the actual status of urban land use, to investigate a number of errors. In the use of high resolution imagery of cities and shape of changes in land use dynamic monitoring of the study area can be a real sense of the dynamic monitoring, which will largely accelerate the formulation of urban development planning and forecasting future trends.

\section{B. Research Abroad}

Abroad, the earlier uses of remote sensing for monitoring land use have changed. U.S. use of land resources satellites in the late $70 \mathrm{~s}$ on land resources survey, the preparation of a land use image maps. In 1976 the British launched the country's remote sensing survey of land use change, the preparation of a national land use maps of 1 : 50000. Since then, Japan, the Philippines, Canada, Australia, have launched a land use survey, the results significantly. To the late $80 \mathrm{~s}$, with the accelerated process of urbanization, global environmental issues and the increasing prominence of sustainable development, urban land use changes more and more attention. In 1995, "International Geosphere-Biosphere Programme" (IGBP) and the "Humanities Programme on Global Environmental Change" (IHDP) edited and published the LUCC Project "research program" has been clearly put forward the land-use change and land use change dynamic mechanism The main content of the research related to the rapid expansion[14,15].

Foreign land use change in urban remote sensing research focuses on several key areas of LUCC: dynamic mechanism of land use, land cover change, LUCC in the regional and global models, LUCC effects and the ecological environment of remote sensing technology in the LUCC of applications. So far, LUCC change and its driving forces carried out earlier, the results are rich, but with the transfer of research priorities, LUCC has also recently been the effect of more concern and attention; in Model regard, there have been, scholars try, but few breakthroughs, which in addition to building and sustainability of the universal model of the difficulty of the research itself, but also subject to the effectiveness of the first three areas and progress [16].

Currently, foreign land-use change on the city's research includes the establishment of the change process and the changes caused by the driving force of its database. With the developing of high resolution remote sensing technologies, the importance of the dynamic monitoring for the changes in urban is growing more and more in recent years. Mundia.CN use of remote sensing image analysis of different periods of urban land use change and dynamic growth process, the last in the socio-economic statistical data, terrain and other factors, aided by the use of GIS analysis to study their spatial and temporal dynamics [17]. And other proposed use of Masek normalized difference vegetation index NDVI and texture characteristics of urban expansion on the Washington area to study and accurately detailed the expansion of the urban area [18]. Coward, etc. using Landsat TM satellite images of earth system science point of view from the city's monitoring of land use change has been studied [19]. Martin, the city is expanding the analysis of remote sensing monitoring of dynamic spatial and temporal scales are analyzed [20]. Urban land use change in the mechanisms of power are more Canadian Pierce, United States, Mcconnell, Bartier and other scholars have studied them, summed up the urban land use change are the driving mechanism of population growth, economic development factors, research areas where the regional conditions and terrain factors $[21,22]$.

\section{CONCLUSION AND DiscUSSION}

Remote sensing of urban land use change monitoring of the key technologies in support of the core of urban land use database technology and access to an important tool for geospatial data, has been rapid development in recent years. Can be achieved using high-resolution remote sensing of urban land use database updates easily and quickly, producing large scale maps, to improve mapping accuracy and speed, promoting eco-city construction, and promote sustainable development, improve the living environment, promote social harmony.

Using high-resolution remote sensing image in remote sensing to monitor land use change in the course of the study fully reflects the systematic, coordinated and sustainable development of other theories. On the basis of systems theory, a holistic approach, rapid urbanization, urban land use under the conditions of change in urban land use change caused by environmental effects, to explore the dynamic process of urban land use in the driving mechanism of urban development land use strategy to determine coordinate relations between people and land, and guide sustainable urban land use and promote the process of urbanization Health Promotion, which is the city's land use change has important remote sensing research significance.

\section{ACKNOWLEDGMENT}

We thank like to express our thanks to editors. This work is supported by the Key project of Shanghai leading academic disciplines of China (Grant No.J50103), and partially by the Key Project of the National Technology Support Program of China (grant No.2008BAC38B03) and key program of Shanghai Science and Technology Committee (Grant No.08DZ2292200).

\section{REFERENCES}

[1] WANG $\mathrm{Ru}$ song. "The frontiers of urban ecological research in industrial transformation". Acta ecologica sinica, vol 20, no5, 2000, pp. 830-840

[2] WU Xian yu. "Discuss city remote sensing". Science mosaic, vol 7, 2006, pp. 119-120

[3] Chengfan Li, Jingyuan Yin, Junjuan Zhao. " Extraction of urban vegetation from high resolution remote sensing image", 2010 International Conference on Computer Design and Applications, vol.1, Qinhuangdao, Hebei, China, June25-27, 2010, pp. 4403-4406.

[4] Chengfan Li, Jingyuan Yin, Junjuan Zhao. "Dynamic analysis of regional land cover change based on TM images", vol.1, Hefei, Anhui, China, August 24-27, 2010, pp. 49-52. 
[5] LI Cheng-fan, ZHOU Ting-gang. "Research on the dynamic change of Chongqing municipal land use based on multi-source remote sensing". Natural resource economics of China. vol 8, 2009, pp.34-37

[6] GU Chao lin. "On research direction of Chinese urban continued development". Urban planning forum, vol 6, 1994, pp. 3-11

[7] LI Cheng-fan, SHI Wei, ZHOU Ting-gang, et al. "Study of remote sensing monitoring and driving forces of the construction land of urban-A case study in Beibei district of Chongqing". Science of surveying and mapping, vol 34, no 3, 2009, pp. 232-234

[8] DING Jun, WANG Dan, WANG Chao peng, et al. "Experiences in the application of high resolution satellite remote sensing technology in land use dynamic monitoring". Geotechnical investigation \& surveying, vol 3, 2005, pp. 59-62

[9] LI Xia. "Spatio-temperal analysis of land use patterns in the development corridor of the Pearl River delta in 1988-1997'. Journal of natural resources, vol 19, no3, 2004, pp. 307-315

[10] ZHANG You quan, GONG Hui li, ZHAO Wen ji, et al. "Analysis the mechanism of land use change in Beijing city from 1990-2000". Resources science, vol 29, no3, 2007, pp. 206-213

[11] WANG Li, NIU Zheng, YIN Jun, et al. "Analysis land use change of small tomns based on RS technology: A case study in Huanghua town". Resources science, vol 28, no5, 2007, pp. 68-75

[12] LI Cheng-fan, SU Ying-chun, ZHOU Ting-gang, et al. "Study of urban land use changes and their effects on eco-environment-A case study of Beibei district of Chongqing". Journal of Southwest University (Natural science edition), vol 30, no 12, 2008, pp. 145-151

[13] CHEN Shu peng, XIE Chuan jie. "Urban remote sensing and urban geo-information system". Developments in surveying and mapping, vol 25, no 1, 2000, pp. 1-8

[14] Desank P.V, Frost P.G.H, Frost C.O, et al. "The Miombo Network : Framework for a Terrestrial Transect Study of Land use and Land cover Change in the Miombo Ecosystems of Central Africa". IGBP:Stochkholm, 1997

[15] Lambin R.F, Baulies X, Bockstael N, et al. "Land use and Land cover Change (LUCC)-Implementation Strategy". IGBP: Stochkholm, 1999

[16] SHI Pei jun, PAN Yao zhong, CHEN Jin, et al. "Land use/ cover change and environmental security in Shenzhen region". Journal of natural resources, vol 14, no 4, 1999, pp. 293-299

[17] Mundia C.N, Aniya M. "Analysis of land use /cover changes and urban expansion of Nairobi city using remote sensing and GIS". International Journal of Remote Sensing, vol 26, no 13, 2005, pp. 2831-2849

[18] J.G.Masek, F.E.Lindsay, S.N.Goward. "Dynamics of urban growth in the Washington DC metropolitan area, 1973-1996, from Landsat observation". International Journal of Remote Sensing, vol 21, no 18, 2000 , pp. $3473-3486$

[19] Coward S.N, Williams D. "Landsat and Earth System Science: development of terrestrial monitoring”. Photogrammetric Engineering and Remote Sensing, vol 63, no 2, 1997, pp. 887 - 900

[20] Herold M, Clarke K.C, Menz G. "A multi-scale framework for mapping and analysis of the spatial and temporal pattern of urban growth". In Proceedings of 22nd EARSEL Symposium Geoinformation for European - wide integration. Prague, June, 2000

[21] John J, Pierce. "Conversion of rural land to urban: a Canada profile". Professional Geographer, 1981

[22] Edward B.Barbier, Joanne C.Burgess. "The economics of tropical forestland use option". Land Economics, vol 73, no 2, 1997, pp. 24-29.

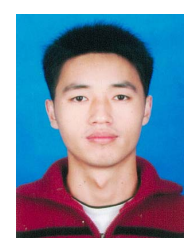

Cheng-fan LI, Male, China, $\mathrm{PhD}$ research student, is a senior member of IACSIT and now with the School of Computer Engineering and Science, Shanghai University, Shanghai, CO 200072 China. He received respectively his BS and MS degrees in Science from the Southwest University in 2005 and 2009. He is the author of dozens of scientific papers. His current research interests include RS and spatial information processing, GIS, InSAR and Geophysics field etc. Phone: +0086-13621734010, 0086-21-66743308,Email: david-0904@163.com, Address: doctoral apartment O3\#207, Shanghai University, 99 Shangda Road, BaoShan District, Shanghai, China. Zip Code: 200444 